\title{
Pengaruh Experiential Marketing Film Dilan 1990 Terhadap Kepuasan Konsumen (Studi Kasus: Mahasiswa Fakultas Ekonomi Universitas Merdeka Madiun)
}

\author{
Novy Rachma Herawati ${ }^{1}$, Andik Susanto ${ }^{2}$ \\ ${ }^{1,2}$ Program Studi Manajemen, Fakultas Ekonomi Universitas Merdeka Madiun \\ ${ }^{1}$ Email: novy@unmer-madiun.ac.id \\ ${ }^{2}$ Email : andiksusanto@unmer-madiun.ac.id
}

\begin{abstract}
Tujuan dari penelitian adalah bagaimana experiental marketing atau pengalaman dari penonton setelah melihat Film Dilan 1990 dan kepuasan konsumen (menonton) yang mereka rasakan setelah melihat film tersebut. Populasi dari penelitian ini adalah Mahasiswa Fakultas Ekonomi Universitas Merdeka Madiun. Sampel penelitian Sampel penelitian adalah Mahasiswa Fakultas Ekonomi Tahun Angkatan 2016. Permasalahan yang akan dibahas yaitu: 1). Apakah strategic experiential modules berpengaruh terhadap kepuasan konsumen dalam melsihat Film Dilan 1990, 2). Apakah experience providers berpengaruh terhadap kepuasan konsumen dalam melihat Film Dilan 1990, 3). Apakah strategic experiential modules dan experience providers secara bersama-sama (simultan) berpengaruh terhadap kepuasan konsumen dalam melihat Film Dilan 1990. Penelitian ini menggunakan teknik purposive sampling yaitu, metode pengambilan sampel dengan pertimbangan tertentu yang disesuaikan dengan kriteria dan tujuan penelitian. Data yang digunakan terdiri dari (1) data primer; yakni data yang diperoleh dengan cara menyebarkan kuesioner kepada responden serta observasi yang dilakukan oleh peneliti, dan (2) data sekunder; yakni data yang diperoleh dari berbagai sumber seperti jurnal, dan sumber literatur lainnya.
\end{abstract}

Kata Kunci: Experiental marketing, Film Dilan 1990, Kepuasan konsumen.

\section{PENDAHULUAN}

A. Latar Belakang

Pentingnya pemasaran merupakan jawaban untuk mengetahui keinginan dan apa yang dibutuhkan oleh pelanggan/pengguna, baik itu produk maupun jasa. Tren dalam pemasaran yang berkembang saat ini lebih mengarah pada pembentukan pengalaman bagi konsumen. Menurut Honantha dan Anandya (2010) Experiential marketing merupakan konsep pemasaran dengan memfokuskan pemberian pengalaman yang berujung pada perilaku pembelian. Di berbagai industri, perusahaan sudah beralih dari pemasaran tradisional yang bersifat "features-and-benefits" menjadi pemasaran yang menciptakan pengalaman bagi konsumen dengan experiential marketing (Schmitt, 1999). Lebih lanjut Schmitt menyebutkan bahwa experiential marketing fokus pada pengalaman konsumen, menganggap konsumsi sebagai sebuah pengalaman secara keseluruhan, memperlakukan konsumen sebagai mahluk yang rasional dan juga emosional. Beberapa peneliti seperti Nunes dan Cespedes (2003) menyebutkan bahwa sisi emosional konsumen berpengaruh terhadap kepuasan konsumen.

Dapat dikatakan bahwa experiential marketing sangatlah penting untuk menciptakan berbagai pengalaman bagi konsumen. Menurut Schmitt (1999) experiential marketing memiliki dua konsep utama yaitu 1) strategic experiential module (SEMs) yang meliputi lima faktor, yaitu faktor sense (panca indera), feel (perasaan), think (cara berpikir), act (perilaku dan kebiasaan), relate (pertalian), dan 2) experience providers (ExPros) yang meliputi communication, visual/verbal identity, product presence, co-branding, spatial environment, website and media electronic, dan people.

Experiential marketing sendiri dapat diterapkan dalam berbagai bidang, termasuk yang akan diteliti disini adalah keterlibatan emosional konsumen (penonton) dalam melihat Film Dilan 1990. Film Dilan 1990 sendiri adalah Film terlaris sepanjang tahun 2018 dengan perolehan jumlah penonton sebanyak 6,2 juta. Film yang dibintangi oleh Iqbaal Ramadhan "Dilan" dan Vanesha Prescilla "Milea" merupakan film remaja yang berlatar belakang tahun 90-an. Film ini juga merupakan film terlaris kedua sepanjang masa dalam sejarah perfilman di Indonesia. Tidak terkecuali dengan Mahasiswa Universitas Merdeka Madiun Fakultas Ekonomi yang tidak melewatkan Film ini dan mendapatkan respon yang luar biasa setelah melihat Film ini, salah satunya adalah penanyangan film yang lama diputar di bioskop karena jumlah penonton yang sangat banyak. Dari sini bisa dilihat bagaimana konsumen merasa puas dan melakukan tindakan berulang. Walaupun kepuasan pelanggan bukanlah satu-satunya tujuan bagi praktisi pemasaran, namun kepuasan merupakan benchmark bagi kinerja perusahaan (Bennett dan Rundle-Thiele, 2004). Berbagai penelitian menyebutkan bahwa memberikan kepuasan pelanggan adalah tujuan utama bisnis saat ini, karena ada hubungan yang sangat erat antara kepuasan pelanggan dan keuntungan perusahaan.

Konsep experiential marketing ini merupakan salah satu perkembangan konsep pemasaran yang disesuaikan dengan keadaan yang berkembang secara dinamis dimana konsumen lebih pintar dan selektif dalam memilih produk. Schmitt (1999) 
menyatakan bahwa konsep pemasaran dan bisnis tradisional hampir tidak memberikan arah untuk memanfaatkan kemunculan ekonomi experiential. Pemasar harus menetapkan lingkungan yang tepat untuk memungkinkan pengalaman yang diinginkan pelanggan. Perusahaan tidak mungkin untuk menjadi kompetitif dengan alat-alat pemasaran tradisional karena manfaat dari produk sekarang semakin lebih mirip. Lebih lanjut disebutkan pada konsep pemasaran tradisional, konsumen dilihat sebagai masyarakat yang berpikir rasional, mereka akan melihat produk dan karakteristiknya serta kelebihannya dibandingkan dengan produk lain. Berbeda dengan konsep pemasaran tradisional, experiential marketing melihat konsumen bukan hanya sebagai pemikir rasional tetapi juga emosional. Konsep experiential marketing digunakan untuk beberapa tujuan, antara lain membangun hubungan, menghasilkan interaksi, memastikan target audiens, meningkatkan kesadaran merek, meningkatan relevansi, meningkatkan loyalitas, meningkatkan keinginan mencoba, menciptakan ingatan atau kenangan. Experiential marketing memotivasi konsumen untuk melakukan pembelian yang lebih cepat dan lebih positif yang pada akhirnya mencapai loyalitas konsumen. Menurut Schmitt (1999) strategi yang dikembangkan dalam experiential marketing dibagi menjadi dua bagian, yaitu Strategic experiential modules (SEMs) dan Experience Providers (ExPros).

Strategic Experiential Modules (SEMs) adalah modul strategi eksperiensial yang dapat digunakan oleh manager untuk menciptakan berbagai tipe pengalaman bagi konsumen. Modul ini mencakup pengalaman sensorik (sense), pengalaman afektif (feel), pengalaman kognitif (think), pengalaman perilaku, gaya hidup (act), dan pengalaman identitas sosial (relate).

Walaupun kepuasan pelanggan bukanlah satu-satunya tujuan bagi praktisi pemasaran, namun kepuasan merupakan benchmark bagi kinerja perusahaan (Bennett dan Rundle-Thiele, 2004). Berbagai penelitian menyebutkan bahwa memberikan kepuasan pelanggan adalah tujuan utama bisnis saat ini, karena ada hubungan yang sangat erat antara kepuasan pelanggan dan keuntungan perusahaan. Menurut Fornell salah satu tujuan utama dari program perilaku kepuasan pelanggan adalah untuk meningkatkan tingkat retensi pelanggan. Sementara itu, Reichheld dan Sasser menyebutkan program kepuasan pelanggan yang disebut-sebut sebagai alat yang penting untuk dapat meningkatkan keuntungan dengan mencegah pelanggan agar tidak berpindah ke perusahaan lain. Kotler dan Keller (2012) menyebutkan bahwa kepuasan adalah perasaan senang atau kecewa seseorang yang muncul setelah membandingkan antara persepsi terhadap kinerja suatu barang atau jasa dengan apa yang diharapkannya. Saat hasil sesuai atau bahkan melebihi ekspektasi, konsumen akan merasa senang dan dikatakan puas atas barang atau jasa yang digunakan. Blackwell et al. (2006) mendefinisikan bahwa kepuasan konsumen merupakan evaluasi purnabeli dimana alternatif yang dipilih sekurang- kurangnya memberi hasil (outcome) sama atau melampui harapan konsumen. Dengan demikian dapat dikatakan bahwa kepuasan pelanggan adalah sesuatu yang dirasakan pelanggan karena perusahaan telah dapat memberikan hasil sama atau melebihi dari harapan pelanggan sehingga merasa senang dan kembali lagi kepada perusahaan yang telah bertransaksi sama mereka.. Dengan demikian dapat dikatakan bahwa walaupun ada beberapa kesamaan dalam definisi kepuasan, namun operasionaliasi definisi kepuasan itu sendiri masih kabur. Penelitian ini mengusulkan langkah-langkah yang didasarkan pada persepsi manajer berpengalaman untuk menilai kepuasan pelanggan dari berbagi kedua perspektif tersebut dengan mendasarkan pada dimensi yang sedang diukur.

Hendarsono (2013) melakukan penelitian untuk mengetahui hubungan antara experiential marketing, experiential value dan purchase intension di resoran cepat saji. Hasil penelitian menunjukkan bahwa experiential marketing adalah pendorong penting yang dapat mempengaruhi nilai pengalaman dan niat pembelian layanan restoran cepat saji. Experiential marketing (sense, merasa, berpikir, bertindak dan berhubungan) dari konsumen akan mempengaruhi niat beli konsumen. Alkilani et al. (2013) melakukan penelitian untuk menganalisis pengaruh experiential marketing dan kepuasan pelanggan terhadap komitmen pelanggan. Hasil Penelitian menunjukan bahwa hanya sense dan feel pada experiential marketing berpengaruh terhadap kepuasan pelanggan dan kepuasan pelanggan berpengaruh terhadap komitmen pelanggan.

Aisyah (2008) melakukan penelitian untuk mengetahui pengaruh penerapan experiential marketing strategic (yang terdiri dari komunikasi, identitas visual, kehadiran produk, kerjasama merek, spatial environment, dan people) terhadap kepuasan konsumen di Cafe Resto Bukit Awan Gresik. Hasil penelitian menunjukkan bahwa keenam variable bebas, yakni komunikasi, identitas visual, kehadiran produk, kerjasama merek, spatial environment, dan people secara parsial dan serentak berpengaruh secara signifikan terhadap kepuasan konsumen.

Astami (2012) melakukan penelitian untuk mengetahui mengenai pengaruh experiential marketing (yang meliputi sense, feel, think, act, dan relate terhadap kepuasan pelanggan The Plaza Semanggi. Hasil penelitian menunjukkan bahwa kelima variable indenpenden tersebut berpengaruh positif dan signifikan terhadap kepuasan konsumen.

Asyifah (2012) melakukan penelitian mengenai pengaruh experiential marketing dan kualitas pelayanan pada kepuasan konsumen dan loyalitas konsumen di The House of Raminten Yogyakarta. Dalam penelitian ini digunakan 2 metode yaitu simple regression untuk mengetahui hubungan antara kepuasan dan loyalitas, serta multiple regression untuk mengetahui hubungan antara experiential marketing, kualitas pelayanan pada kepuasan konsumen. Hasil penelitian menunjukkan bahwa terdapat pengaruh signifikan dan positif antara experiential marketing pada kepuasan konsumen.

Biaya pemasaran merupakan

Berdaskan latar belakang dirumuskan permasalahan bagaimana experiental marketing atau pengalaman dari penonton setelah melihat Film Dilan 1990 terhadap kepuasan yang mereka rasakan. Kepuasan atau mungkin rasa yang dialami oleh konsumen tentunya bisa menimbulkan kegiatan yang berulang seperti melihat filmnya lagi atau mungkin membeli atau mengoleksi barang-barang yang terkait dengan Film Dilan 1990. 
Tujuan dari penelitian ini diantaranya adalah sebagai berikut:

1. Untuk menguji pengaruh strategic experiential modules berpengaruh terhadap kepuasan konsumen dalam melihat Film Dilan 1990.

2. Untuk menguji experience providers berpengaruh terhadap kepuasan konsumen dalam melihat Film Dilan 1990.

3. Untuk menguji strategic experiential modules dan experience providers secara bersama-sama (simultan) berpengaruh terhadap kepuasan konsumen dalam melihat Film Dilan 1990.

\section{B. Kerangka Pemikiran dan Hipotesis}

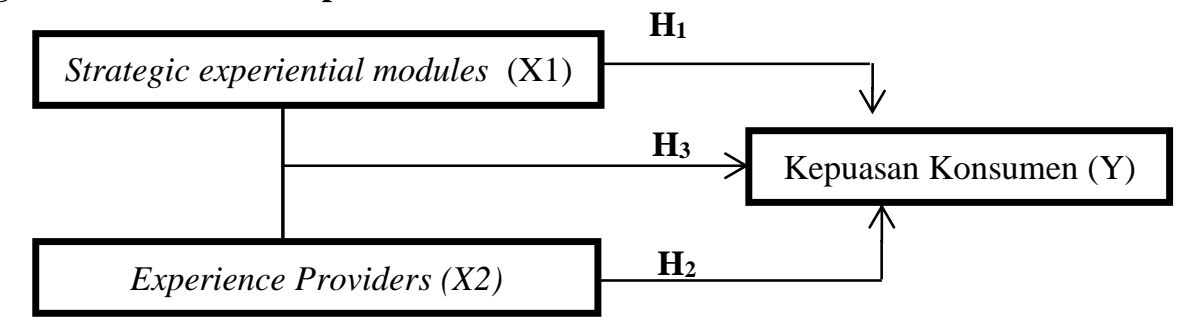

Gambar 1. Kerangka Pemikiran

\section{Hipotesis:}

H1 : strategic experiential modules berpengaruh terhadap kepuasan konsumen dalam melihat Film Dilan 1990

$\mathbf{H}_{2}$ : experience providers berpengaruh terhadap kepuasan konsumen dalam melihat Film Dilan 1990

$\mathbf{H}_{3}$ : strategic experiential modules dan experience providers secara bersama-sama (simultan) berpengaruh terhadap kepuasan konsumen dalam melihat Film Dilan 1990.

\section{METODE PENELITIAN}

Metode yang digunakan untuk penelitian ini adalah kuantitatif, dengan jenis penelitian yang digunakan adalah hubungan causal (causal effect). Menurut Sugiyono (2016:7), "Metode penelitian kuantitatif dapat diartikan sebagai metode penelitian yang berlandaskan pada filsafat positivisme, digunakan untuk meneliti pada populasi atau sampel tertentu". Teknik pengambilan sampel pada umumnya dilakukan secara random, pengumpulan data menggunakan instrumen penelitian, analisis data bersifat kuantitatif/statistik dengan tujuan untuk menguji hipotesis yang telah ditetapkan.

Populasi penelitian ini adalah Mahasiswa Fakultas Ekonomi Universitas Merdeka Madiun Tahun Angkatan 2016 berjumlah 131 mahasiswa. Sampel penelitian adalah Mahasiswa Fakultas Ekonomi Tahun Angkatan 2016 yang sudah menonton Film Dilan 1990. Rescoe mengatakan bahwa penentuan ukuran sampel yang lebih besar dari 30 dan kurang dari 500 adalah jumlah yang sesuai dan wajar untuk penelitian pada umumnya (Sekaran dan Bougie, 2010). Dalam menentukan besaran jumlah sampel peneliti menggunakan Rumus Slovin sebagai berikut :

$$
n=\frac{N}{1+N e^{2}}
$$

Dengan :

$\mathrm{n}=$ Ukuran sampel

$\mathrm{N}=$ Ukuran populasi

$\mathrm{e} \quad=$ Persen kelonggaran (error) sebesar 0,01 (10\%)

Jumlah populasi sebanyak 131 mahasiswa dengan presentasi kelonggaran (error) adalah 0,01 (10\%). Maka sampel penelitian:

$$
n=\frac{131}{1+131(0,01)^{2}}=56,7 \text { atau dibulatkan } 57 \text { mahasiswa }
$$

Penelitian ini menggunakan teknik purposive sampling yaitu, metode pengambilan sampel dengan pertimbangan tertentu yang disesuaikan dengan kriteria dan tujuan penelitian (Sekaran dan Bougie, 2010). Kriteria responden yang dapat mengisi kuesioner penelitian ini, antara lain (1) usia responden minimal 17 tahun, dan (2) sudah pernah melihat Film Dilan 1990. Skala Pengukuran dalam penelitian ini digunakan skala Likert.

Data primer diperoleh dengan cara menyebarkan kuesioner kepada responden serta observasi yang dilakukan oleh peneliti, dalam memperoleh data primer ini peneliti menyebarkan kuesioner kepada mahasiswa yag sudah pernah menonton film. Data sekunder diperoleh dari berbagai sumber seperti jurnal, dan sumber literatur lainnya, untuk penelitian sumber yang digunakan adalah berdasarkan dari jurnal-jurnal penelitian yang sudah dilakukan sebelumnya.

Definisi Operasional Variabel dalam penelitian ini adalah: 
1. Variabel terikat dalam penelitian ini adalah kepuasan konsumen (Y). Kepuasan adalah perasaan senang atau kecewa seseorang yang muncul setelah membandingkan antara perpsepsi atau kesannya terhadap kinerja (atau hasil) suatu produk dengan harapan-harapannya.

Kepuasan konsumen diukur dengan indikator:

a. Nilai yang diperoleh sesuai dengan harga yang dibayarkan,

b. Konsumen puas dengan kualitas produk (film) yang bagus,

c. Konsumen ingin mengulangi hal yang sama (melihat film)

2. Variabel bebas dalam penelitian ini adalah:

\section{a. Strategic Experiential Modules (X1)}

1) Sense experience (X1) diukur dengan indikator:

- Tampilan gambar yang bagus,

- Rasa yang diberikan oleh film dapat dihayati oleh penonton atau penikmat film,

- Suara dari film yang bagus,

- Alur cerita yang dapat dipahami,

- Aktor dan aktris (pemeran film )yang good looking

2) Feel experience (X2) diukur dengan indikator:

- Promo film yang menarik untuk konsuman,

- Iklan yang terus-menerus dengan mengendors tokoh Dilan 1990

- Berita-berita yang update tentang Film Dilan, baik melalui media social atau website resmi dari PH yang memproduksi.

3) Think (X3) diukur dengan indikator sebagai berikut:

- Kesesuaian harga dengan produk yang didapat sudah menjawab kebutuhan konsumen,

- Film Dilan 1990 memberikan kualitas film yang bagus untuk konsuman,

- Film Dilan menawarkan sequel seperti Dilan 1991 dan Milea, yang merupakan kelanjutan dari film Dilan 1990.

4) Act experience (X4) diukur dengan indikator:

- Citra yang dimiliki Film Dilan 1990 sangat baik,

- Image pemain Film Dilan 1990 dapat meningkatkan prestige,

- Reputasi sutradara dan penulis Novel Film Dilan 1990 tidak dapat diragukan keahliannya.

5) Relate (X5) diukur dengan indikator sebagai berikut:

- Kisah Cinta Remaja tahun 1990 menjadi daya tarik untuk ditonton,

- Gombalan atau kata-kata rayuan Dilan menarik untuk dilihat,

- Pemain Film yang good looking, sutradara dan penulis Novel yang terkena menjadi alasan untuk menonton film Dilan.

\section{b. Experience Providers (X2)}

Experience Providers (ExPros) (Schmitt, 1999): Experience providers sebagai implementasi taktis yang siap digunakan pemasar untuk menciptakan pengalaman bagi konsumen. Expros mencakup tujuh komponen yaitu:

1) Communication meliputi iklan Filam Dilan 1990 yang menarik,

2) Visual/verbal identity. Logo dan warna Film Dilan yang mencolok

3) Product presence. Tampilan Film Dilan yang menarik

4) Co-branding. Sponsor Film Dilan banyak dan semuanya sudah dikenal oleh masyarakat.

5) Spatial Environment, PH yang memproduksi Film Dilan 1990 adalah gabungan PH besar antara Max Picture dan Falcon Picture

6) Web Sites and Electronic Media (Situs Internet dan Media Elektronik. Situs perusahaan terupdate setiap waktu, sehingga informasi apapun bisa didapatkan di website perusahaan.

7) People (Orang). Karyawan di PH yang memproduksi Film Dilan 1990 sangat ramah kepada penggemar.

Teknik analisa data yang digunakan adalah analisis statistik deskriptif yang memberikan gambaran suatu data yang dilihat berdasarkan nilai rata-rata (mean) dan standar deviasi, Uji Asumsi Klasik, Analisa Regresi Linear Berganda, Koefisien Korelasi Berganda (R), Koefisien Determinasi (R2 ), Uji F, dan Uji t. Aplikasi yang digunakan adalah SPSS Version 25. 


\section{HASIL DAN PEMBAHASAN}

\section{A. Karakteristik Responden}

Untuk mendapatkan data primer yang dilakukan adalah menyebarkan kuesioner untuk mengetahui tanggapan responden atau mahasiswa yang telah melihat film Dilan 1990. Penyebaran kuesioner dilakukan terhadap 57 mahasiswa orang responden yang terdiri dari 35 mahasiswi dan 22 mahasiswa. Berikut ini adalah karakteristik responden berdasarkan dengan jenis kelamin:

Tabel 1

Karakteristik berdasarkan Jenis Kelamin Responden

\begin{tabular}{|l|c|c|}
\hline \multicolumn{1}{|c|}{ Jenis Kelamin } & Frekuensi & Prosentase (\%) \\
\hline Laki-laki & 22 & $39 \%$ \\
\hline Perempuan & 35 & $61 \%$ \\
\hline Total & 57 & $100 \%$ \\
\hline
\end{tabular}

B. Analisis Data

a. Uji Validitas

Hasil pengolahan data untuk uji Validitas dapat dilihat dalam tabel berikut ini :

1. Variabel Sense Experience (X1)

Tabel 2

Rangkuman hasil uji Validitas Sense Experience (X1)

\begin{tabular}{|c|c|c|c|c|}
\hline No & Item & r hitung & r tabel & Keterangan \\
\hline 1 & 1 & 0,85 & 0,25 & Valid \\
\hline 2 & 2 & 0,85 & 0,25 & Valid \\
\hline 3 & 3 & 0,81 & 0,25 & Valid \\
\hline 4 & 4 & 0,41 & 0,25 & Valid \\
\hline 5 & 5 & 0,33 & 0,25 & Valid \\
\hline
\end{tabular}

Sumber: Data Primer yang diolah

Dengan menggunakan tingkat signifikan $(\alpha) 5 \%$ atau 0,05 dari 5 butir atau item kuesioner penelitian ini, hasil pengujian validitas menunjukan bahwa $\mathrm{r}$ hitung lebih besar dari pada $\mathrm{r}$ tabel yang artinya seluruh butir atau (item) instrumen penelitian memiliki hubungan yang "signifikan" dengan skor total. Dengan demikian, 5 butir (item) variabel Sense experience (X1) tersebut adalah "valid" atau sah digunakan sebagai instrumen pengukuran dalam penelitian ini.

2. Variabel Feel Experience (X2)

Tabel 3

Rangkuman hasil uji Validitas Feel experience (X2)

\begin{tabular}{|c|c|c|c|c|}
\hline No & Item & r hitung & r tabel & Keterangan \\
\hline 1 & 1 & 0,73 & 0,25 & Valid \\
\hline 2 & 2 & 0,82 & 0,25 & Valid \\
\hline 3 & 3 & 0,71 & 0,25 & Valid \\
\hline
\end{tabular}

Sumber: Data Primer yang diolah

Dengan menggunakan tingkat signifikan $(\alpha) 5 \%$ atau 0,05 dari 3 butir atau item kuesioner penelitian ini, hasil pengujian validitas menunjukan bahwa $r$ hitung lebih besar dari pada $r$ tabel yang artinya seluruh butir atau (item) instrumen penelitian memiliki hubungan yang "signifikan" dengan skor total. Dengan demikian, 3 butir (item) variabel Feel experience (X2) tersebut adalah "valid" atau sah digunakan sebagai instrumen pengukuran dalam penelitian ini.

3. Variabel Think (X3)

\section{Tabel 4}

Rangkuman hasil uji Validitas Variabel Think (X3)

\begin{tabular}{|c|c|c|c|c|}
\hline No & Item & r hitung & r tabel & Keterangan \\
\hline 1 & 1 & 0,89 & 0,25 & Valid \\
\hline 2 & 2 & 0,88 & 0,25 & Valid \\
\hline 3 & 3 & 0,86 & 0,25 & Valid \\
\hline
\end{tabular}

Sumber: Data Primer yang diolah

Dengan menggunakan tingkat signifikan $(\alpha) 5 \%$ atau 0,05 dari 3 butir atau item kuesioner penelitian ini, hasil pengujian validitas menunjukan bahwa $r$ hitung lebih besar dari pada $r$ tabel yang artinya seluruh butir atau (item) 
instrumen penelitian memiliki hubungan yang "signifikan" dengan skor total. Dengan demikian, 3 butir (item) variabel

Think (X3) tersebut adalah "valid" atau sah digunakan sebagai instrumen pengukuran dalam penelitian ini.

\section{Variabel Act Experience (X4)}

Tabel 5

Rangkuman hasil uji Validitas Variabel Act Experience (X4)

\begin{tabular}{|c|c|c|c|c|}
\hline No & Item & r hitung & r tabel & Keterangan \\
\hline 1 & 1 & 0,89 & 0,25 & Valid \\
\hline 2 & 2 & 0,86 & 0,25 & Valid \\
\hline 3 & 3 & 0,85 & 0,25 & Valid \\
\hline
\end{tabular}

Sumber: Data Primer yang diolah

Dengan menggunakan tingkat signifikan $(\alpha) 5 \%$ atau 0,05 dari 3 butir atau item kuesioner penelitian ini, hasil pengujian validitas menunjukan bahwa $r$ hitung lebih besar dari pada $r$ tabel yang artinya seluruh butir atau (item) instrumen penelitian memiliki hubungan yang "signifikan" dengan skor total. Dengan demikian, 3 butir (item) variabel Act experience (X4) tersebut adalah "valid" atau sah digunakan sebagai instrumen pengukuran dalam penelitian ini.

\section{Variabel Relate $(\mathrm{X5})$}

Tabel 6

Rangkuman hasil uji Validitas Variabel Relate (X5)

\begin{tabular}{|c|c|c|c|c|}
\hline No & Item & r hitung & r tabel & Keterangan \\
\hline 1 & 1 & 0,83 & 0,25 & Valid \\
\hline 2 & 2 & 0,75 & 0,25 & Valid \\
\hline 3 & 3 & 0,77 & 0,25 & Valid \\
\hline
\end{tabular}

Sumber: Data Primer yang diolah

Dengan menggunakan tingkat signifikan $(\alpha) 5 \%$ atau 0,05 dari 3 butir atau item kuesioner penelitian ini, hasil pengujian validitas menunjukan bahwa $r$ hitung lebih besar dari pada $r$ tabel yang artinya seluruh butir atau (item) instrumen penelitian memiliki hubungan yang "signifikan" dengan skor total. Dengan demikian, 3 butir (item) variabel Relate (X5) tersebut adalah "valid" atau sah digunakan sebagai instrumen pengukuran dalam penelitian ini.

Variable Experience Providers $\left(\mathrm{X} 2_{1}\right)$ didapatkan hasil uji validitas sebagai berikut:

Tabel 7

Rangkuman hasil uji Validitas Experience Providers (X2

\begin{tabular}{|c|c|c|c|c|}
\hline No & Item & r hitung & r tabel & Keterangan \\
\hline 1 & 1 & 0,26 & 0,25 & Valid \\
\hline 2 & 2 & 0,73 & 0,25 & Valid \\
\hline 3 & 3 & 0,57 & 0,25 & Valid \\
\hline 4 & 4 & 0,81 & 0,25 & Valid \\
\hline 5 & 5 & 0,74 & 0,25 & Valid \\
\hline 6 & 6 & 0,81 & 0,25 & Valid \\
\hline 7 & 7 & 0,74 & 0,25 & Valid \\
\hline
\end{tabular}

Dengan menggunakan tingkat signifikan $(\alpha) 5 \%$ atau 0,05 dari 7 butir atau item kuesioner penelitian ini, hasil pengujian validitas menunjukan bahwa $r$ hitung lebih besar dari pada $r$ tabel yang artinya seluruh butir atau (item) instrumen penelitian memiliki hubungan yang "signifikan" dengan skor total. Dengan demikian, 7 butir (item) variabel Experience Providers (X21) tersebut adalah "valid" atau sah digunakan sebagai instrumen pengukuran dalam penelitian ini.

\section{b. Uji Reliabilitas}

Suatu data instrumen dikatakan reliabel apabila memiliki nilai Cronbach's Alpha >0,60. Adapun kriteria item pertanyaan dikatakan reliable atau handal dapat dilihat dari beberapa kriteria indeks reliabilitas sebagai berikut:

Tabel 8

Kriteria Indeks Reliabilitas

\begin{tabular}{|c|c|c|}
\hline No & Interval & Kriteria \\
\hline 1 & $<0,200$ & Sangat Rendah \\
\hline 2 & $0,200-0,399$ & Rendah \\
\hline 3 & $0,400-0,599$ & Cukup \\
\hline 4 & $0,600-0,799$ & Tinggi \\
\hline 5 & $0,800-1,000$ & Sangat Tinggi \\
\hline
\end{tabular}


Hasil pengujian reliabilitas (tabel 9) pada variable sense experience (X1), Feel experience (X2), Think (X3), Act experience (X4), Relate (X5) adalah reliabel dan layak untuk digunakan sebab seluruh nilai alpha hitung lebih tinggi dari Alpha Cronbach 0,6.

Tabel 9

Rangkuman hasil uji Reliabilitas

\begin{tabular}{|c|c|c|c|c|}
\hline No & Variabel & Alpha hitung & Alpha Cronbach & Keterangan \\
\hline 1 & $\mathrm{X}_{1}$ & 0,73 & 0,6 & Reliabel \\
\hline 2 & $\mathrm{X}_{2}$ & 0,62 & 0,6 & Reliabel \\
\hline 3 & $\mathrm{X}_{3}$ & 0,83 & 0,6 & Reliabel \\
\hline 4 & $\mathrm{X}_{4}$ & 0,85 & 0,6 & Reliabel \\
\hline 5 & $\mathrm{X}_{5}$ & 0,68 & 0,6 & Reliabel \\
\hline
\end{tabular}

Sumber : Data primer yang diolah

Hasil pengujian reliabilitas (tabel 10) pada variable experience providers $\left(\mathbf{X 2}_{1}\right)$ yang terdiri dari communication (XI), visual/verbal identity (X2), product presence (X3), co-branding (X4), spatial environment (X5), web sites and electronic media (x6), dan People (x7) menunjukkan reliabel dan layak sebab seluruh nilai alpha hitung lebih besar dari nilai Cronbach Alpha 0,6.

Tabel 10

Rangkuman hasil uji Reliabilitas

\begin{tabular}{|c|c|c|c|c|}
\hline No & Variabel & Alpha hitung & Alpha Cronbach & Keterangan \\
\hline 1 & $\mathrm{X}_{1}$ & 0,85 & 0,60 & Reliabel \\
\hline 2 & $\mathrm{X}_{2}$ & 0,69 & 0,60 & Reliabel \\
\hline 3 & $\mathrm{X}_{3}$ & 0,74 & 0,60 & Reliabel \\
\hline 4 & $\mathrm{X}_{4}$ & 0,67 & 0,60 & Reliabel \\
\hline 5 & $\mathrm{X}_{5}$ & 0,69 & 0,60 & Reliabel \\
\hline 6 & $\mathrm{X}_{6}$ & 0,67 & 0,60 & Reliabel \\
\hline 7 & $\mathrm{X}_{7}$ & 0,68 & 0,60 & Reliabel \\
\hline
\end{tabular}

Sumber: Data Primer yang diolah

c. Analisi Regresi Linier Berganda

Analisis regresi linier berganda dilakukan untuk mengetahui pengaruh sense experience (X1), feel experience (X2), think experience (X3), act experience (X4), relate experience (X5) serta variabel Kepuasan Konsumen (Y) dalam menonton Film Dilan 1990.

Berikut ini adalah hasil analisis regresi linear berganda dengan menggunakan program SPSS Versi 25.

Tabel 11

Analisis Regresi Linier Berganda

\begin{tabular}{|l|l|}
\hline Model & Koefisien \\
\hline Konstanta & 0.162 \\
\hline sense experience $(\mathrm{X} 1)$ & 0.213 \\
\hline feel experience $(\mathrm{X} 2)$ & 0.263 \\
\hline think experience $(\mathrm{X} 3)$, & 0.206 \\
\hline act experience $(\mathrm{X} 4$ & 0.105 \\
\hline relate experience $(\mathrm{X} 5)$ & 0.196 \\
\hline
\end{tabular}

Sumber: Data Primer diolah

Model Regersi Linier berganda dalam penelitian ini adalah:

d. Uji F

$\mathrm{Y}=0.612+0.213 \mathrm{X} 1+0.263 \mathrm{X} 2+0.206 \mathrm{X} 3+0.105 \mathrm{X} 4+0.196 \mathrm{X} 5$.

Diketahui nilai $\mathrm{F}$ hitung adalah sebesar 43.60 serta nilai signifikansi uji $\mathrm{F}$ yang nilainya kurang dari $0.05(\alpha=5 \%)$. Hasil ini dapat disimpulkan bahwa model regresi yang dihasilkan telah cocok (fit) digunakan untuk mengetahui hubungan pengaruh antara variabel bebas yaitu sense experience (X1), feel experience (X2), think experience (X3), act experience (X4), relate experience (X5) terhadap variabel Kepuasan Konsumen (Y) Dari hasil ini maka hipotesis pertama penelitian dapat diterima kebenarannya. 
e. Uji t

Dari hasil penelitian menunjukka bahwa variabel bebas sense experience (X1), feel experience (X2), think experience (X3), dan relate experience (X5) masing-masing menghasilkan nilai signifikansi t hitung yang lebih kecil dari 0.05 ( $\alpha=5 \%$ ) yaitu 0.00 untuk X1, 0.00 untuk X2, 0.00 untuk X3, dan 0.01 untuk X5 . Dari hasil ini ini maka dapat disimpulkan bahwa secara parsial masing-masing variabel tersebut yaitu bebas sense experience (X1), feel experience (X2), think experience (X3), relate experience (X5) memiliki pengaruh yang signifikan terhadap Kepuasan Konsumen menonton Film Dilan 1990, atau dengan kata lain apabila performa masing-masing dari sense experience (X1), feel experience (X2), think experience (X3), dan relate experience (X5) semakin baik, maka minat konsumen untuk menonton kembali Film Dilan 1990 semakin meningkat. Dari penelitian ini juga dapat diketahui bahwa signifikansi t hitung dari variabel Act experience (X4) adalah sebesar 0.10, dimana nilai ini lebih besar dari $0.05(\alpha=5 \%)$ sehingga dapat disimpulkan bahwa secara parsial variabel Act experience (X4) tidak berpengaruh signifikan terhadap Kepuasan Konsumen menonton Film Dilan 1990.

f. Uji Hipotesis

\section{Pengujian Hipotesis Pertama}

Hipotesis pertama $\left(\mathbf{H}_{\mathbf{1}}\right)$ pada penelitian ini menguji pengaruh strategic experiential modules berpengaruh terhadap kepuasan konsumen setelah melihat Film Dilan 1990. Pengaruh Strategic Experiential Modules Terhadap Kepuasan Konsumen Hasil uji hipotesis (H1) menunjukkan bahwa strategic experiential modules berpengaruh terhadap kepuasan konsumen dengan nilai koefisien 0,826 pada tingkat signifikansi 0,000. Dengan demikian, dapat dikatakan, semakin baik penerapan strategic experiential modules, maka akan kepuasan konsumen akan semakin meningkat. Hasil penelitian ini sejalan dengan hasil penelitian Astami (2012). Dalam penelitian tersebut disebutkan bahwa strategic experiential modules berpengaruh pada kepuasan konsumen secara positif dan signifikan. Alasan mengapa strategic experiential modules berpengaruh pada kepuasan konsumen antara lain, karena Film Dilan 1990 ini disutradai oleh sutradara yang sudah terkenal dan diangkat dari novel yang sudah menjadi best seller. Secara umum dapat dikatakan bahwa strategic experiential modules Film Dilan 1990 ini telah menciptakan berbagai jenis pengalaman bagi konsumen, yang meliputi: 1) pengalaman Sense, yakni pengalaman yang dirasakan oleh konsumen melalui panca indera, seperti mata, telinga, hidung, kulit, dan lidah; 2) pengalaman Feel, yakni pengalaman yang dirasakan oleh konsumen melalui suasana hati, perasaan, dan emosi konsumen; 3) pengalaman Think, yakni pengalaman yang dirasakan melalui ajakan untuk berpikir secara konvergen maupun divergen bagi konsumen; 4) pengalaman Act, yakni pengalaman yang disampaikan kepada konsumen melalui adanya interaksi, aksi, ataupun hubungannya dengan gaya hidup konsumen; 5) pengalaman Relate yakni pengalaman yang disampaikan kepada konsumen dengan mengaitkan diri konsumen dengan idealisasi dirinya dan luar pribadinya, seperti komunitas atau konsumen lainnya. Saat kelima pengalaman tersebut dapat disampaikan dengan baik kepada konsumen, maka mereka akan akan merasa senang dan puas.

\section{Pengujian Hipotesis Kedua}

Pengaruh Experience Providers Terhadap Kepuasan Konsumen Hasil uji hipotesis (H2) menunjukkan bahwa experience providers berpengaruh terhadap kepuasan konsumen dengan nilai koefisien 0,397 pada tingkat signifikan 0,000. Hasil ini menunjukkan bahwa semakin baik experience providers yang digunakan, maka akan semakin meningkatkan kepuasan konsumen. Hal ini menunjukkan bahwa experience providers telah sesuai kriteria yang diinginkan oleh sebagian besar konsumen. Penerimaan hipotesis ini didukung pula dengan hasil penelitian Aisyah (2008) yang menyebutkan bahwa experience providers berpengaruh positif dan signifikan terhadap kepuasan konsumen. Alasan mengapa experience providers berpengaruh pada kepuasan konsumen antara lain, karena experience providers yang digunakan dalam menyampaikan pengalaman kepada konsumen merupakan alat yang dapat diamati atau dirasakan langsung oleh konsumen. Experience providers ini meliputi komunikasi seperti iklan; identitas visual/verbal.

\section{Pengujian Hipotesis Ketiga}

Pengaruh Strategic Experiential Modules dan Experience Providers secara serentak Terhadap Kepuasan Konsumen Strategic Experiential Modules dan Experience Providers merupakan dua inti utama dalam Experiential Marketing (Schmitt, 1999). Apabila kedua inti tersebut diterapkan bersama-sama maka akan menciptakan sebuah kepuasan konsumen. Berdasarkan hasil uji F diketahui bahwa strategic experiential modules dan experience providers secara serentak berpengaruh terhadap kepuasan konsumen, karena memiliki nilai F positif sebesar 110,531 dengan tingkat signifikansi sebesar 0,000. Hasil ini menunjukkan bahwa hipotesis ketiga (H3) diterima. Hasil penelitian ini sejalan dengan hasil penelitian yang dilakukan oleh Asyifah (2012). Strategic experiential modules dan experience providers secara serentak berpengaruh secara positif dan signifikan terhadap kepuasan konsumen. Hasil hipotesis ini juga didukung oleh hasil penelitian Cheng dan Yu (2009) yang menyatkan bahwa pengalaman konsumen memiliki pengaruh yang positif terhadap kepuasan konsumen dimana dengan memberikan pengalaman yang baik dan berharga bagi konsumen dapat menjadi kunci kesuksesan perusahaan di pasar yang kompetitif. Hasil penelitian menunjukkan bahwa nilai koefisien strategic experiential modules memiliki nilai yang lebih tinggi dibandingkan dengan variabel experience providers. 


\section{IV.KESIMPULAN}

\section{A. Kesimpulan}

Berdasarkan hasil analisis dapat diambil kesimpulan sebagai berikut :

1. Berdasarkan hasil pengujian hipotesis pertama ditemukan bahwa strategic experiential modules berpengaruh terhadap kepuasan konsumen dalam melihat Film Dilan 1990.

2. Berdasarkan hasil pengujian hipotesis kedua ditemukan bahwa experience providers berpengaruh terhadap kepuasan konsumen dalam melihat Film Dilan 1990.

3. Berdasarkan hasil pengujian hipotesis ketiga ditemukan bahwa strategic experiential modules dan experience providers B. Saran secara bersama-sama (simultan) berpengaruh terhadap kepuasan konsumen dalam melihat Film Dilan 1990.

Saran yang dapat dijadikan pertimbangan, yaitu :

1. Perusahaan atau Production House sebaiknya dapat meningkatkan penerapan experiential marketing karena hasil pengujian hipotesis menunjukkan bahwa experiential marketing memberikan pengaruh yang positif dan signifikan terhadap kepuasan konsumen. Hal ini diharapkan dapat berdampak pada loyalitas konsumen untuk kelangsungan hidup perusahaan. Perusahaan sebaiknya lebih menekankan peningkatan pada strategic experiential modules, karena faktor ini memiliki nilai koefisien yang lebih besar dibandingkan dengan experience providers. Namun perlu diperhatikan bahwa strategic experiential modules dan experience providers merupakan bagian dari experiential marketing yang saling berhubungan dan saling mendukung satu sama lain sehingga peningkatan penggunaan experience providers seperti komunikasi, identitas visual/verbal, kehadiaran produk, co-branding, lingkungan spasial, situs dan media elektronik, serta karyawan atau orang yang bertugas menyampaikan pelayan pada konsumen, perlu juga dilakukan oleh perusahaan.

2. Pada penelitian selanjutnya sebaiknya dilakukan penelitian untuk menganalisis pengaruh antar dimensi baik dimensi strategic experiential modules maupun dimensi experience providers sehingga bisa dilihat dimensi mana dari setiap variabel tersebut berpengaruh terhadap kepuasan konsumen. Disamping itu, nilai koefosien determinasi (R2) sebesar 0,695 menunjukkan bahwa kedua variabel (strategic experiential modules dan experience providers) hanya mampu menjelaskan $69,5 \%$ variasi kepuasan konsumen.

\section{DAFTAR PUSTAKA}

Aisyah, N. (2008), Pengaruh Penerapan Experiential Marketing Strategic Terhadap Kepuasan Konsumen di Cafe Resto Bukit Awan Gresik. (Skripsi), Universitas Muhammadiyah Gresik.

Alkilani, K., Ling K.C., dan Abzakh, A.A. (2013), The Impact of Experiential Marketing and Customer Satisfaction on Customer Commitment in the World of Social Networks. Asian Social Science; Vol. 9, No. 1.

Astami, N. (2012), Analisis Pengaruh Experiential Marketing Terhadap Kepuasan Pelanggan The Plaza Semanggi (Skripsi), Program Studi Manajemen Fakultas Ekonomi Unika Atma Jaya Jakarta.

Asyifah Y.D.A. (2012), Analisis Pengaruh Experiential Marketing dan Kualitas Pelayanan pada Kepuasan Konsumen dan Loyalitas Konsumen di The House of Raminten. (Tesis) Penerbit Universitas Gadjah Mada, Yogyakarta.

Bennett, R. dan Rundle-Thiele S. (2004), Customer Satisfaction Should not be the only goal. Journal of Services Marketing, Vol. 18 No. 7 pp. $514-523$.

Blackwell, R.D., Miniard, P.W., dan Engel J.F (2006), Consumer Behavior, 10th ed. Thomson, Singapore.

Cheng, N.K. dan Yu, H.C. (2009), An Examination of The Relationship between Experiential Marketing, Participative Motivation, Customer Satisfaction, and Customer Loyalty: The National Taiwan University Indoor Swimming Pool. Taipei: 17th EASM Conference.

Hendarsono, G. (2013), Analisa Pengaruh Experiential Marketing Terhadap Minat Beli Ulang Konsumen Cafe Buntos 99 Sidoarjo. Jurnal Strategi Pemasaran Vol. 1, No. 2.

Honanta, C.R. dan Anandya, D. (2010), Experiential Marketing, Customer Satisfaction, Behavioral Intention: Timezone Game Center Surabaya. International Conference Business and Economics, April, pp. 1-6.

Kotler, P. dan Keller, K.L. (2012), Marketing Management, 14th ed. New Jersey: Pearson Prentice Hall. Kurnia, N. (2006), Lambannya Pertumbuhan Industri Perfilman. Jurnal Ilmu Sosial dan Ilmu Politik, 9, pp. 271-296. Lee, J., Lee,J., dan Feick, L. (2001). The impact of switching costs on the customer satisfactionloyalty link: mobile phone service in France. Journal of Services Marketing, 15, pp. 35-48.

Nunes, P.E. dan Cespedes, F.V. (2003), The Customer Has Escaped. Harvard Business Review, 81, pp. 96-105.

Schmitt, B. (1999), Experiential Marketing. Journal of Marketing Management, 15, 1-3, pp. 53-67.

Sekaran, U. dan Bougie, R. (2010), Research Methods for Business: a skill building approach, 5th edition. United Kingdom: John Wiley \& Son Ltd.

Sugiyono (2016), Metode Penelitian Pendidikan Pendekatan Kuantitatif, Kualitatif, dan R \& D. Bandung: Alfabeta. 